\title{
Intrinsic flexibility of snRNA hairpin loops facilitates protein binding
}

\author{
MICHAEL RAU, ${ }^{1}$ W. TOM STUMP, ${ }^{1}$ and KATHLEEN B. HALL ${ }^{2}$ \\ Department of Biochemistry and Molecular Biophysics, Washington University Medical School, St. Louis, Missouri 63110, USA
}

\begin{abstract}
Stem-loop II of U1 snRNA and Stem-loop IV of U2 snRNA typically have 10 or 11 nucleotides in their loops. The fluorescent nucleobase 2-aminopurine was used as a substitute for the adenines in each loop to probe the local and global structures and dynamics of these unusually long loops. Using steady-state and time-resolved fluorescence, we find that, while the bases in the loops are stacked, they are able to undergo significant local motion on the picosecond/nanosecond timescale. In addition, the loops have a global conformational change at low temperatures that occurs on the microsecond timescale, as determined using laser T-jump experiments. Nucleobase and loop motions are present at temperatures far below the melting temperature of the hairpin stem, which may facilitate the conformational change required for specific protein binding to these RNA loops.
\end{abstract}

Keywords: 2-aminopurine fluorescence; RNA hairpin loops; snRNA stem-loops

\section{INTRODUCTION}

Hairpins are the mainstay of RNA structures, as they provide nucleation sites for folding (the UUCG tetraloop), tertiary structure staples (tetraloop/tetraloop receptors), binding sites for $\mathrm{Mg}^{2+}$ ions, and binding sites for proteins. These local secondary structures can form during transcription, thus restricting secondary structure conformations of the overall RNA and, at the same time, providing rapid access to the RNA by ligands that bind to hairpin loops. Thermodynamically, an RNA loop is destabilizing: The presence of a loop adds an unfavorable free energy term. Measured and predicted values of free energies for initiating a hairpin loop of $n$ nucleotides $\left[\Delta \mathrm{G}^{\circ}{ }_{37 \mathrm{iL}(n)}\right]$ are surprisingly similar for $n=$ 4-9: from +4.9 to $+5.5 \mathrm{kcal} / \mathrm{mol}$ (Serra et al. 1997).

However, there are several conserved biological systems that contain long RNA loops. One highly conserved example is the 15-nt sarcin-ricin loop in $23 \mathrm{~S}$ and $28 \mathrm{~S}$ rRNA. This loop is notable for its structured fold which includes a basetriple, noncanonical base pairs, a tetraloop, and a compressed overall structure (Correll et al. 1999, 2003). Other long loops are found in the vertebrate $\mathrm{U} 1$ and $\mathrm{U} 2$ snRNA components of the $\mathrm{U} 1$ and $\mathrm{U} 2$ snRNPs, respectively, that together have a

\footnotetext{
${ }^{1}$ These authors contributed equally to this work.

${ }^{2}$ Corresponding author

E-mail kathleenhal@gmail.com

Article published online ahead of print. Article and publication date are at http://www.rnajournal.org/cgi/doi/10.1261/rna.035006.112.
}

total of nine hairpins, of which three have loops of 10 or more nucleotides (Reddy et al. 1981; Krol et al. 1990). The secondary structures of the human U1 snRNA Stem-loop II (SLII) and the U2 snRNA Stem-loop IV (SLIV) from human and Drosophila are shown in Figure 1 and are the subject of this study.

The three longest hairpin loops in U1 and U2 snRNAs are binding sites for proteins: U1 SLI is bound by U1 $70 \mathrm{~K}$ protein (Query et al. 1989); U1 SLII by U1A or SNF (Scherly et al. 1989; Flickinger and Salz 1994; Polycarpou-Schwartz et al. 1996); and U2 SLIV by U2B" or SNF (Scherly et al. 1990). The loop nucleotides must be available for recognition by these sequence-specific RNA binding proteins, which leads to the question of the mechanism for binding. The cocrystal structures (Oubridge et al. 1994; Price et al. 1998) of U1A:SLII and U2B":SLIV illustrate how the protein invades the RNA loop to make specific contacts with nucleotides: Some nucleobases become stacked with tyrosine and phenylalanine sidechains, while others form hydrogen bonds to the protein backbone. The mechanism of the binding reaction could entail trapping a single loop structure that can be bound by the protein (conformational capture) (Williamson 2000) or making one RNA:protein contact that facilitates subsequent rearrangements of RNA and protein to form the final complex (induced fit) (Frankel and Smith 1998); of course, the reality is likely to be more complicated. Indeed, several possible mechanisms and schemes for U1A binding to SLII have been proposed (Katsamba et al. 2001; Pitici et al. 2002; Showalter and Hall 2002, 2004; Kormos et al. 2007; Qin et al. 2010; 

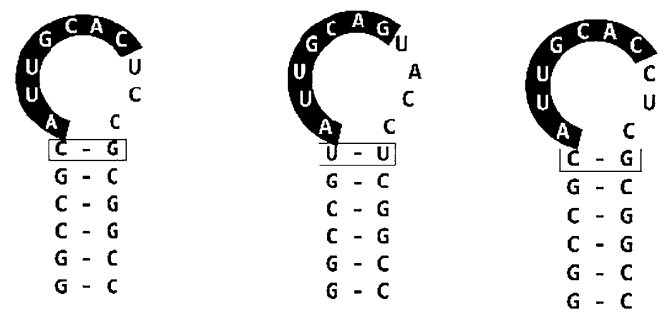

\begin{tabular}{lccc} 
Human SLII & Human SLIV & Drosophila SLII & Drosophila SLIV \\
\hline$\Delta G^{\circ}$ stem $=-15.8 \mathrm{kcal} / \mathrm{mol}$ & $-12.4 \mathrm{kcal} / \mathrm{mol}$ & $-15.8 \mathrm{kcal} / \mathrm{mol}$ & $-14.9 \mathrm{kcal} / \mathrm{mol}$ \\
$\Delta \mathrm{G}^{\circ}$ loop $=+5.00 \mathrm{kcal} / \mathrm{mol}$ & $+5.3 \mathrm{kcal} / \mathrm{mol}$ & $+5.0 \mathrm{kcal} / \mathrm{mol}$ & $+6.3 \mathrm{kcal} / \mathrm{mol}$ \\
$\Delta \mathrm{G}^{\circ}(\mathrm{fold})=-10.8 \mathrm{kcal} / \mathrm{mol}$ & $-7.1 \mathrm{kcal} / \mathrm{mol}$ & $-10.8 \mathrm{kcal} / \mathrm{mol}$ & $-8.6 \mathrm{kcal} / \mathrm{mol}$
\end{tabular}

FIGURE 1. Sequences of the three stem-loops (SL) or hairpins used here. SLIV from human and Drosophila differ in their loop-closing base pair. For all calculations, the free energies for loops include the loop-closing base pair. For hSLII, calculations are for a 6-bp stem; for hSLIV, the stem is $5 \mathrm{bp}$; and for dSLIV, the stem is $6 \mathrm{bp}$. Folding free energies were calculated using mfold (Zuker 2003).

Anunciado et al. 2011) and may generally apply to SLIV binding by SNF and U2B". Curiously, there are few studies that examine the properties of the hairpin loops in solution.

Intrinsic loop structure and dynamics are important parameters to define in order to understand how the RNA nucleobases come to be displayed for protein contacts (Luchansky et al. 2000; Law et al. 2006). Structural constraints of the free RNA loops appear to be minimal, since there are no apparent base pairs that form across the loop, although stacking interactions should be present (Shajani and Varani 2005). However, the extent of the flexibility has not been studied in detail, particularly with regard to the dynamics of the loops. Since it is not possible to experimentally describe all the conformational states accessible to the RNA, we ask a more focused question that addresses SLII and SLIV intrinsic flexibility in solution, using 2-aminopurine (2AP) steady-state and time-resolved fluorescence to probe loop environments and dynamics. We find that at or below room temperature, the bases are stacked, particularly those on the $3^{\prime}$ side of SLIV. The nucleobases at the loop apex have less stacking and more flexibility. Bases are moving on the $\mathrm{psec} / \mathrm{nsec}$ timescale, and motions at the apex and side of the loop appear to be uncorrelated. The loop also undergoes $\mu$ sec motions, at least below room temperature. When SLII is in a complex with U1A (Shajani et al. 2007), the $3^{\prime}$ UCC sequence at the side of the SLII loop is disordered (Showalter and Hall 2005). We found similar behavior for U2 SLIV bound to Drosophila SNF: The nucleotides on the 3' side of the loop acquire rapid local motions as they are not part of the RNA:protein interface. The local motions of both loops in their free state are most apparent near the apex, while when bound to protein, the $3^{\prime}$ side of the loop becomes more flexible.

\section{RESULTS AND DISCUSSION}

To probe the structure and dynamics of the loops, the fluorescent base 2-aminopurine replaced the adenosines in

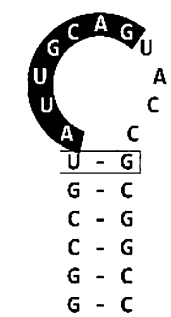

the loops. Stem-loop II has two adenosines, one at the $5^{\prime}$ base of the loop adjacent to the stem and the other at the apex of the loop. Stem-loop IV contains these two adenosines and also has a third on the $3^{\prime}$ side of the loop. The temperature and salt dependences of RNAs with a single $2 \mathrm{AP}$ were compared in steadystate and time-resolved fluorescence experiments to characterize the loops.

\section{Stem-loop IV}

A comparison of 2AP fluorescence intensity and UV-absorption of the RNA as a function of temperature shows that the loop nucleobases are changing their environments before the hairpin stem denatures (melts) (Fig. 2). The loop is undergoing structural changes that alter the exposure of the 2AP to solvent and to adjacent stacked bases.

2AP steady-state fluorescence intensity varies dramatically with $2 \mathrm{AP}$ position, indicating that the physical environments of the nucleobases are not equivalent. Fluorescence of 2AP at the apex of the loop in Drosophila SLIV (dSLIV) has an approximately twofold greater intensity than $2 \mathrm{AP}$ on the $3^{\prime}$ side. Fluorescence of $2 \mathrm{AP}$ at the $5^{\prime}$ end of the loop is severely quenched; its fluorescence intensity is 10 -fold less than that of the apical 2AP. Since base stacking is the most effective quenching mechanism for 2AP fluorescence, the simplest interpretation of these data is that the $5^{\prime} 2 \mathrm{AP}$ is stacked over the loop-closing U:G base pair. By implication, the stem structure is propagated into the loop, stacking at least the flanking bases as in an A-form duplex. In contrast, $2 \mathrm{AP}$ at the apex is flanked by a $5^{\prime}$ cytosine and $3^{\prime}$ guanosine in SLIV, but its fluorescence intensity is high, suggesting that it is often unstacked. 2AP on the $3^{\prime}$ side has about one-half the intensity of $2 \mathrm{AP}$ at the apex, suggesting that it spends more of its time stacked with its flanking uridine and cytidine. Since uracil has little propensity to stack (Burkard et al. 1999), it seems likely that most of the stacking would come from the $3^{\prime}$ cytosine. At lower temperatures, our model of SLIV includes stacking of its $5^{\prime}$ adenosine on the loop-closing base pair and the three $3^{\prime}$ side (ACC) nucleobases stacked on each other, with the $3^{\prime}$ cytosine stacked on the loop-closing base pair such that the A-form duplex structure is propagated into the loop.

The temperature response of the 2AP fluorescence also reveals a great deal about how the loop structure/flexibility is changing. The fluorescence intensity of the $5^{\prime} 2 \mathrm{AP}$ is unchanged from $5^{\circ} \mathrm{C}$ to $55^{\circ} \mathrm{C}$, showing that its environment is constant. Its fluorescence begins to increase coincident with stem melting (measured by UV absorbance), indicating that stacking of the $2 \mathrm{AP}$ on the $\mathrm{U}: \mathrm{G}$ base pair is one of the first interactions to be destabilized as the hairpin melts. 
A)

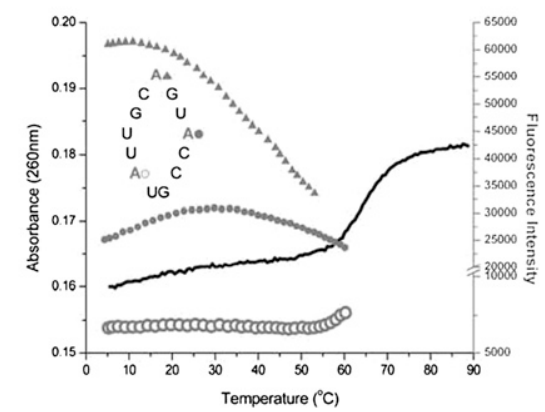

C)

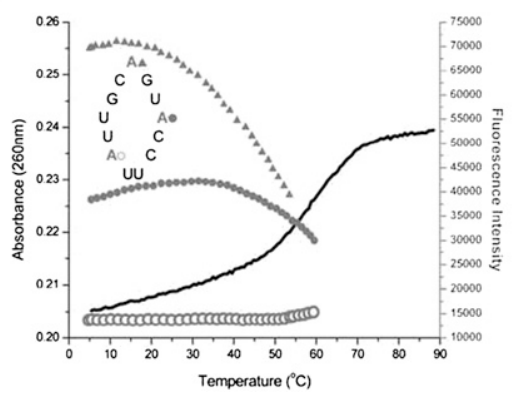

FIGURE 2. Thermal denaturation of SLIV hairpins. (A) dSLIV. Fluorescence of $2 \mathrm{AP}$ at the

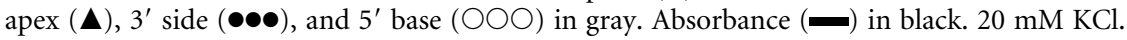
$(B)$ Salt dependence of dSLIV melting and 3' side 2AP loop fluorescence. Solid lines, in buffer with no added salt; dotted lines, in $100 \mathrm{mM} \mathrm{KCl}$. Black lines are absorbance; gray lines are fluorescence. $(C)$ hSLIV. Fluorescence of $2 \mathrm{AP}$ at the apex $(\mathbf{\Delta}), 3^{\prime}$ side $(\bullet \bullet \bullet)$, and $5^{\prime}$ base (○○○). Absorbance at $260 \mathrm{~nm}(-)$ in $20 \mathrm{mM} \mathrm{KCl}$. Absorbance monitored at $260 \mathrm{~nm}$, fluorescence intensity at $366 \mathrm{~nm}$. [RNA] $=2 \mu \mathrm{M}$. Buffer: $2.5 \mathrm{mM}$ sodium cacodylate $\mathrm{pH} 7.4$, $250 \mu \mathrm{M}$ EDTA. Low salt was used to eliminate dimerization of the RNA.

$2 \mathrm{AP}$ at the apex of the loop has its maximum fluorescence intensity at $\leq 15^{\circ} \mathrm{C}$, then rapidly loses intensity with increasing temperature. Some of the loss of fluorescence intensity is due to collisional quenching with solvent molecules, which becomes more efficient at higher temperatures (Lakowicz 2006). However, the temperature dependence of $2 \mathrm{AP}$ in the loop is distinct from that of $2 \mathrm{AP}$ nucleotide in solution (see Fig. 3B) and requires another explanation. A ready interpretation of these data is that the loop structure around the apex where the RNA strand presumably bends becomes more mobile above $20^{\circ} \mathrm{C}$, so that $2 \mathrm{AP}$ has an increased number of encounters with flanking nucleobases. Transient stacking interactions and collisions with solvent lead to quenching of its fluorescence at temperatures that are below the stem melting temperature, indicating that this part of the loop is flexible.

$2 \mathrm{AP}$ at the loop apex has the highest fluorescence intensity of all the sampled positions, but its properties are not consistent with a completely unstacked extruded nucleobase. 2AP nucleotide in solution at the equivalent concentration has 10-fold greater fluorescence intensity at $5^{\circ} \mathrm{C}$ than does $2 \mathrm{AP}$ at the apex of the loop. As Figure 3 illustrates, free $2 \mathrm{AP}$ steady-state fluorescence intensity de- creases almost linearly with temperature from $5^{\circ} \mathrm{C}$ to $65^{\circ} \mathrm{C}$. Its temperature-dependent loss of fluorescence intensity is due to collisional quenching with solvent molecules, which also occurs with 2AP in the loop. However, 2AP in the loop does not begin to lose fluorescence until $\sim 20^{\circ} \mathrm{C}$, indicating that the loop is becoming more flexible: Stacking is becoming transient, and the nucleobases are exposed to solvent.

The fluorescence intensity of $2 \mathrm{AP}$ on the $3^{\prime}$ side of the loop supports the idea that this part of the loop retains stacking until the whole RNA is beginning to unfold. This $2 \mathrm{AP}$ has a relatively constant fluorescence intensity from $5^{\circ} \mathrm{C}$ to $40^{\circ} \mathrm{C}$ (but with a measurable increase at $30^{\circ} \mathrm{C}$ ) which is twofold lower than the apical 2AP fluorescence. Our model of these data is that the $3^{\prime} 2$ APCC sequence is stacked on the U:G loop closing base pair over this temperature range, effectively reducing $2 \mathrm{AP}$ fluorescence intensity. The subsequent loss of fluorescence intensity from $40^{\circ} \mathrm{C}$ to $60^{\circ} \mathrm{C}$ is evidence that the loop is becoming more flexible before the absorbance data show that the stem is melting.

This interpretation is supported by the salt dependence of loop and stem structures. In buffer with no added salt, the melting temperature of the stem is near $50^{\circ} \mathrm{C}$, while in $100 \mathrm{mM} \mathrm{KCl}$, it shifts to $\sim 75^{\circ} \mathrm{C}$. As Figure $2 \mathrm{~B}$ shows, there is a concomitant shift in the fluorescence intensity of $3^{\prime} 2 \mathrm{AP}$, indicating that the structural stability of the loop is also dependent on added counterions. This shift is not accompanied by a change in the shape of the curve, indicating that the local structure is not altered by the added salt.

For these experiments, we used two SLIV sequences that differ in their loop-closing base pair: Drosophila SLIV is closed by a U:G base pair; in human SLIV (hSLIV), this becomes a $U / U$ sequence. The presence of the $U / U$ alters the equilibrium of hairpin/dimer, for hSLIV forms a dimer under some conditions where dSLIV remains a hairpin. The thermal denaturation profile of hSLIV is characterized by a sloping lower baseline (Fig. 2C); it is important to note that these data were acquired in buffer with $20 \mathrm{mM} \mathrm{KCl}$ at 2 $\mu \mathrm{M}$ RNA, where hSLIV is a monomer. In this denaturation curve as well as the others, we attribute the sloping lower baseline to unstacking of the loop nucleobases. The difference in the absorbance data for dSLIV and hSLIV illustrates how the U:G to U/U change affects loop stability and stem melting: The stem melts at $65^{\circ} \mathrm{C}$ for dSLIV and at $60^{\circ} \mathrm{C}$ for hSLIV, consistent with the predicted free energies of the stems (Fig. 1). 
A)

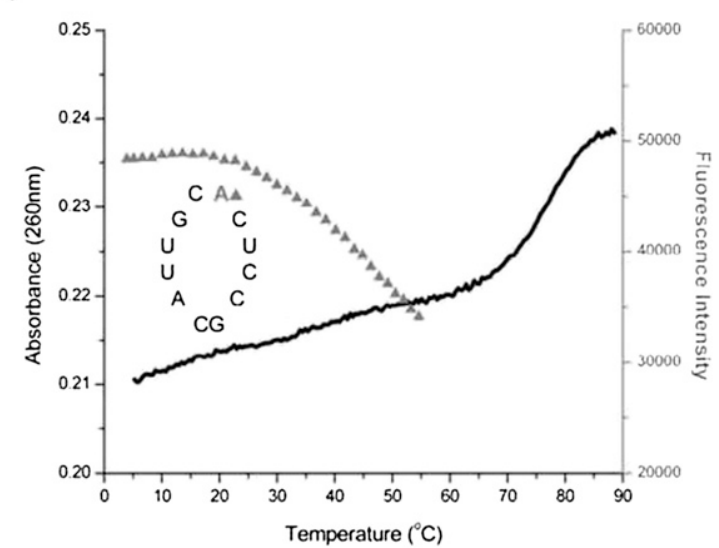

B)

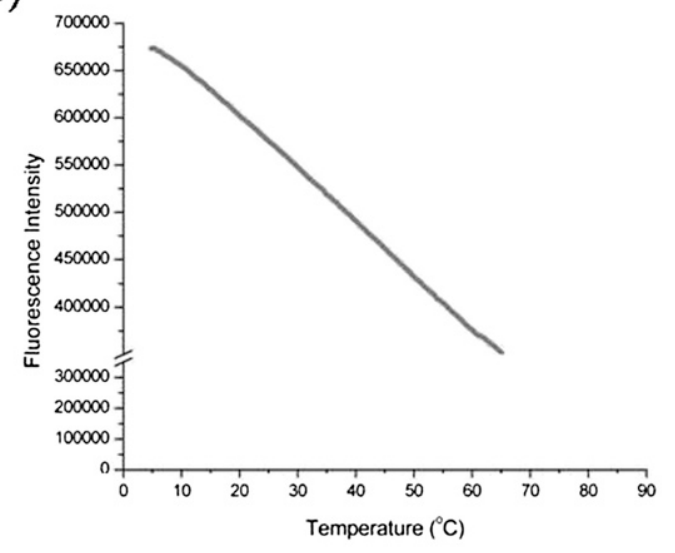

FIGURE 3. Thermal denaturation of human SLII and temperature dependence of free 2AP fluorescence. (A) SLII absorption (black) and 2AP loop fluorescence (gray). $2 \mathrm{AP}$ is at the loop apex. $20 \mathrm{mM} \mathrm{KCl}$. Low-salt buffer was used to eliminate dimerization of the RNA. [RNA] $=2 \mu \mathrm{M}$. $(B)$ Fluorescence intensity of $2 \mathrm{AP}$ nucleotide in solution as a function of temperature. $2 \mu \mathrm{M} 2 \mathrm{AP}$ nucleotide in $2.5 \mathrm{mM}$ sodium cacodylate, $\mathrm{pH} 7.4$, $250 \mu \mathrm{M}$ EDTA.

The fluorescence intensity of each $2 \mathrm{AP}$ in hSLIV is similar to the corresponding $2 \mathrm{AP}$ in $\mathrm{dSLIV}$, with the notable exception of 2AP at the $5^{\prime}$ end of the loop. Although hSLIV 5' 2AP fluorescence is quenched, it is brighter by twofold than in the same position in dSLIV. This difference is likely to be due to its flanking $\mathrm{U} / \mathrm{U}$ sequence that does not form a stable base pair. NMR spectra of the imino protons of these two hairpins show that the dSLIV G:U wobble pair is observed until $40^{\circ} \mathrm{C}$, but because hSLIV RNA forms a dimer at NMR concentrations, we cannot determine if the $U / U$ forms a $U: U$ base pair (data not shown). 2AP on the $3^{\prime}$ side of the hSLIV loop loses fluorescence intensity more rapidly above $30^{\circ} \mathrm{C}$ than does the analogous 2AP in dSLIV, again indicating that this loop stacking is not as robust. In general, hSLIV appears to be less structured in all salt conditions than dSLIV.

\section{SLII}

For this hairpin, we have only two positions for 2AP substitutions, and of these, $2 \mathrm{AP}$ at the $5^{\prime}$ end of the loop gives barely detectable fluorescence. This base stacks over the C:G loop-closing base pair which quenches it until the stem begins to melt. Its low fluorescence yield precludes its use in subsequent experiments.

2AP at the apex of SLII has its highest fluorescence intensity at low temperatures $\left(5^{\circ} \mathrm{C}\right.$ to $20^{\circ} \mathrm{C}$ in $\left.20 \mathrm{mM} \mathrm{KCl}\right)$ (Fig. 3A). Its initial fluorescence intensity is lower by 1.25 to 1.44-fold than the apical 2AP in SLIVs, suggesting that it stacks with its neighboring cytosine nucleobases. The stem of this RNA melts at a higher temperature $\left(78^{\circ} \mathrm{C}\right)$ than those of SLIV due to its C:G loop-closing base pair; as before, we attribute the sloping lower baseline of the absorbance to loop nucleobase unstacking.

\section{Time-correlated single photon counting of 2AP fluorescence}

Time-correlated single photon counting (TCSPC) provides an indication of the number of conformational states of a fluorophore, based on the number of measurable decay lifetimes and their amplitudes. 2AP alone in solution has a single decay lifetime of $\sim 10-11$ nsec. However, 2AP in the context of a molecule can have several lifetimes as a result of its environments. Here, we can report up to three decay lifetimes given the time resolution of our instrument, but those are sufficient to compare environments of each 2AP.

When 2AP in the context of the hairpins has a lifetime component comparable to that of free $2 \mathrm{AP}$, we conclude that it spends time in an environment that isolates it from the rest of the molecule. The amplitude of that long component is a measure of what proportion of the time it spends in that state. 2AP at the apex of SLIV and SLII loops has a significant proportion of a long lifetime $\left(\tau_{1}=8-9 \mathrm{nsec}\right)$ (Table 1), especially in dSLIV where its fractional amplitude is $\sim 0.20$ of the signal. This proportion decreases with temperature, presumably because the movements of adjacent nucleobases in the loop bring them into juxtaposition with the 2AP, therefore changing its photophysics. In contrast, $2 \mathrm{AP}$ on the $3^{\prime}$ side of SLIV has a fractional amplitude $\left(\beta_{1}\right)$ on average of approximately 0.10 to 0.12 with $\tau_{1}=7-8 \mathrm{nsec}$, consistent with this $2 \mathrm{AP}$ being predominantly stacked with occasional excursions to a "flipped out" environment.

Fluorescence of 2AP at the apex of SLII and SLIV has $\tau_{2}=2-2.6 \mathrm{nsec}$, the amplitude of which is temperaturedependent. In both SLIV RNAs, this component contributes $\sim 0.22-0.24$ of the fluorescence decay at lower temperatures; the lifetime becomes shorter, and its amplitude becomes greater at $30^{\circ} \mathrm{C}-40^{\circ} \mathrm{C}$. In SLII, the lifetime is similar, but the 
TABLE 1. 2-aminopurine fluorescence decay lifetimes

\begin{tabular}{|c|c|c|c|c|c|c|c|c|}
\hline Hairpin & $\begin{array}{c}\mathrm{T} \\
\left({ }^{\circ} \mathrm{C}\right)\end{array}$ & $\begin{array}{c}\tau_{1} \\
\text { (nsec) }\end{array}$ & $\beta_{1}$ & $\begin{array}{c}\tau_{2} \\
\text { (nsec) }\end{array}$ & $\beta_{2}$ & $\begin{array}{c}\tau_{3} \\
\text { (nsec) }\end{array}$ & $\beta_{3}$ & $x^{2}$ \\
\hline \multirow[t]{5}{*}{ hSLII apex } & 5 & 8.54 & 0.17 & 2.51 & 0.17 & 0.29 & 0.67 & 2.02 \\
\hline & 10 & 8.05 & 0.18 & 2.52 & 0.17 & 0.27 & 0.64 & 1.93 \\
\hline & 20 & 7.15 & 0.18 & 2.45 & 0.21 & 0.24 & 0.61 & 1.78 \\
\hline & 30 & 6.05 & 0.18 & 2.16 & 0.29 & 0.23 & 0.56 & 1.67 \\
\hline & 40 & 4.77 & 0.17 & 1.77 & 0.29 & 0.22 & 0.54 & 1.67 \\
\hline \multirow[t]{5}{*}{ hSLIV apex } & 5 & 8.92 & 0.20 & 2.48 & 0.22 & 0.29 & 0.58 & 2.04 \\
\hline & 10 & 8.58 & 0.20 & 2.52 & 0.23 & 0.30 & 0.57 & 2.07 \\
\hline & 20 & 7.82 & 0.19 & 2.50 & 0.26 & 0.30 & 0.55 & 1.96 \\
\hline & 30 & 6.86 & 0.17 & 2.28 & 0.30 & 0.29 & 0.53 & 1.97 \\
\hline & 40 & 5.58 & 0.15 & 1.92 & 0.33 & 0.29 & 0.52 & 1.85 \\
\hline \multirow[t]{5}{*}{ dSLIV apex } & 5 & 8.98 & 0.22 & 2.64 & 0.23 & 0.32 & 0.55 & 2.01 \\
\hline & 10 & 8.61 & 0.21 & 2.60 & 0.24 & 0.31 & 0.54 & 2.05 \\
\hline & 20 & 7.82 & 0.21 & 2.59 & 0.27 & 0.32 & 0.52 & 1.90 \\
\hline & 30 & 6.79 & 0.19 & 2.35 & 0.30 & 0.32 & 0.52 & 1.95 \\
\hline & 40 & 5.46 & 0.17 & 1.90 & 0.33 & 0.29 & 0.50 & 1.79 \\
\hline \multirow[t]{5}{*}{ hSLIV side } & 5 & 8.78 & 0.10 & 2.03 & 0.15 & 0.27 & 0.75 & 2.80 \\
\hline & 10 & 8.47 & 0.11 & 2.21 & 0.14 & 0.26 & 0.74 & 2.94 \\
\hline & 20 & 7.37 & 0.12 & 2.13 & 0.17 & 0.22 & 0.71 & 2.78 \\
\hline & 30 & 6.08 & 0.12 & 1.88 & 0.19 & 0.17 & 0.70 & 2.75 \\
\hline & 40 & 4.51 & 0.13 & 1.45 & 0.23 & 0.14 & 0.64 & 2.84 \\
\hline \multirow[t]{5}{*}{ dSLIV side } & 5 & 8.55 & 0.10 & 1.96 & 0.14 & 0.23 & 0.76 & 2.93 \\
\hline & 10 & 8.26 & 0.11 & 2.22 & 0.14 & 0.23 & 0.75 & 2.83 \\
\hline & 20 & 7.04 & 0.12 & 2.08 & 0.16 & 0.19 & 0.73 & 2.66 \\
\hline & 30 & 5.69 & 0.12 & 1.75 & 0.18 & 0.15 & 0.70 & 2.57 \\
\hline & 40 & 4.36 & 0.14 & 1.40 & 0.22 & 0.13 & 0.64 & 2.72 \\
\hline
\end{tabular}

$2 \mathrm{AP}$ at the apex or on the $3^{\prime}$ side of SLIV hairpins. Amplitudes ( $\beta$ ) are given in fraction of total signal; their error from fits is $\leq 5 \%$ of the value shown. $2 \mu \mathrm{M}$ RNA in $20 \mathrm{mM} \mathrm{KCl}, 2.5 \mathrm{mM}$ sodium cacodylate, $\mathrm{pH}$ 7.4. Data fit with FluoFit.

amplitude is notably less $\left(\beta_{2}=0.17\right)$. A physical interpretation of this component is that $2 \mathrm{AP}$ is stacked with other nucleobases, but the stacking geometry (base overlap) is not perfect. For 2AP on the $3^{\prime}$ side of the loop where base stacking is relatively stable, the amplitude of the $\tau_{2} \approx 2 \mathrm{nsec}$ component is reduced to $0.15-0.16$ from $5^{\circ} \mathrm{C}-20^{\circ} \mathrm{C}$, consistent with the physical interpretation that this intermediate lifetime is reporting on imperfectly stacked states.

The largest amplitude component for all 2AP sites has the shortest lifetime $\left(\tau_{3}=200-300 \mathrm{psec}\right.$ at low temperatures). For $2 \mathrm{AP}$ at the SLIV and SLII loop apex, this component contributes more than half of the signal. That this contribution is virtually identical for this $2 \mathrm{AP}$ in both hairpins is interesting, since the nucleobases flanking 2AP in SLII and SLIV are not the same. SLII has the sequence C2APC, while SLIV has the sequence C2APG, and while stable purinepurine stacking leads to more extensive mixing of the electronic states (Jean and Hall 2001, 2002), the fluorescence data suggest that the two environments are very similar. For $2 \mathrm{AP}$ at the $3^{\prime}$ side, this short component dominates the decay, especially at low temperature where its fractional amplitude has a range of $\beta_{3}=0.70-0.76$, consistent with our physical model in which this $2 \mathrm{AP}$ spends most of its time stacked. Given the parameters of our TCSPC instrument, it is likely that the shortest lifetimes are not accurately measured; several unresolved short components could be present. Nevertheless, the physical interpretation is that the bases are stacked with a geometry that facilitates rapid decay of the fluorescence signal (Jean and Hall 2004).

In summary, the TCSPC data show that $2 \mathrm{AP}$ is sampling several conformations with respect to other bases. Even at the apex of the loop, 2AP still spends a significant amount of time aligned with other bases. Conversely, 2AP on the side of the loop is extruded from the stacked conformation only some of the time. The picture is one of a dynamic loop, although the timescale of nucleobase motions is not defined by these experiments; some measure of the timescales of loop and $2 \mathrm{AP}$ motions come from time-resolved anisotropy measurements.

\section{Time-resolved fluorescence anisotropy}

Fluorescence depolarization of a fluorophore occurs when the molecule moves away from its orientation as it absorbs a photon to a new orientation when it emits a photon. The fluorescence depolarization (anisotropy) of 2AP alone in solution is extremely rapid $(\sim 9 \mathrm{psec})$, reflecting the rapid tumbling (rotational correlation time) of the small molecule. In the context of a larger RNA, 2AP fluorescence depolarization can report on local (segmental) motion of the nucleobase as well as the global tumbling time of the entire molecule. Theoretically, the hairpins present several complexities that arise from their irregular shape and internal motions, so we use the most basic interpretation of the results: One component of the anisotropy is due to segmental motion of $2 \mathrm{AP}$, and the other measures global rotational correlation time of the RNA. The data are fit to the standard expression $r(t)=\beta_{1} e^{-t / \varphi 1}+\beta_{2} e^{-t / \varphi 2}$, where $\mathrm{r}(\mathrm{t})$ is the time-dependent anisotropy, $\beta_{n}$ the amplitude of $n$ component, and $\varphi_{n}$ the rotational correlation time of $n$ component $(n=1,2)$.

These data for the three hairpins are shown in Figure 4 as a function of temperature. The longer component, which we assign to the rotational correlation time of the RNA, is independent of the position of the 2AP and decreases as expected with increasing temperature as the viscosity of the solution decreases and the molecule tumbles more rapidly. At low temperature, the rotational correlation time of the hairpins is $\sim 5 \mathrm{nsec}$, which is reasonable for an RNA this size and shape (a 6-bp stem and a partially floppy loop could resemble a sphere or a squat prolate ellipsoid). The reduction in the correlation time to $3 \mathrm{nsec}$ at $20^{\circ} \mathrm{C}$ and an average of $2 \mathrm{nsec}$ at $30^{\circ} \mathrm{C}-40^{\circ} \mathrm{C}$ could be complicated by contributions from the local motion of $2 \mathrm{AP}$ in the loop. In particular, the accuracy of the data at $40^{\circ} \mathrm{C}$ is dubious, since the values of the two depolarization times are so similar that their separability is unlikely (Supplemental Table S1).

A brief discussion of the global and local motions of the RNAs illustrates our interpretations of these fluorescence 
A)

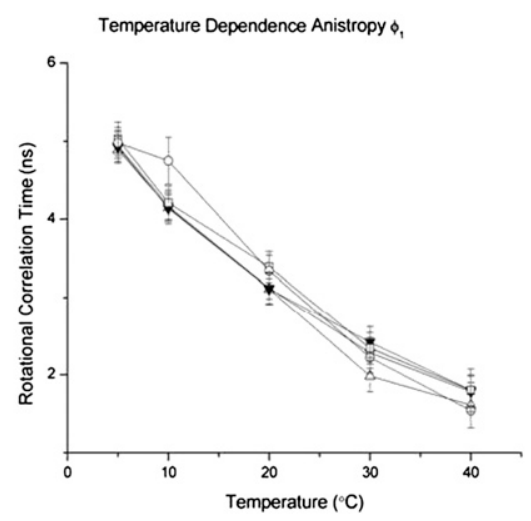

B)

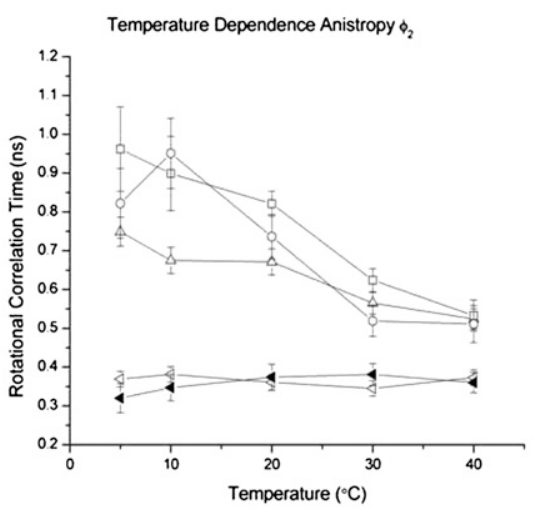

FIGURE 4. Time-resolved anisotropy of 2AP in SLII and SLIV as a function of loop position and temperature. Decay curves were fit to the expression $r(t)=\beta_{1} \mathrm{e}^{-\mathrm{t} / \varphi 1}+\beta_{2} \mathrm{e}^{-\mathrm{t} / \phi 2}$, and the long and short depolarization components $\varphi 1$ and $\varphi 2$ are plotted. (A) The long depolarization component as a function of temperature. (B) The short depolarization component as a function of temperature. $(\bigcirc)$ dSLIV side, $(\square)$ hSLIV side, $(\triangle)$ SLII apex, $(\triangleleft)$ dSLIV apex, (४) hSLIV apex.

data. The rotational correlation time is the parameter we are interested in for the fluorescence anisotropy measurements. The rotational correlation time $\theta$ is related to the rotational diffusion coefficient $\mathrm{D}_{\mathrm{r}}$ (for a spherical particle) as $\theta=\left(6 \mathrm{D}_{\mathrm{r}}\right)^{-1}$ where $\mathrm{D}_{\mathrm{r}}=\mathrm{k}_{\mathrm{B}} \mathrm{T} / 8 \pi \eta \mathrm{r}^{3}\left(\mathrm{k}_{\mathrm{B}}\right.$ is the Boltzmann constant, $\mathrm{T}$ temp in $\mathrm{K}, \eta$ the viscosity of solvent at $\mathrm{T}$, and $\mathrm{r}$ the radius of the particle). The hairpin has a 6-bp stem, so $6^{\star}(2.8 \AA / \mathrm{bp})=16.8 \AA$ stem length $+3^{\star}(2.8 \AA / \mathrm{bp})$ [assuming that the first three nucleotides on either side of the loop are stacked, at least at low temperature] $=25.2 \AA$ of A-form duplex. The 4-5 nt around the apex of the loop could be structured or floppy, so we add another $2.8 \AA$ for good measure, giving a length of $28 \AA$ or about one turn of an A-form duplex. The width of the duplex is $\sim 30 \AA$, so assume a sphere with a radius of $15 \AA$ for simplicity. These parameters in a spherical model produce a rotational correlation time of $3.3 \mathrm{nsec}$ at $22^{\circ} \mathrm{C}(295 \mathrm{~K})$, which is very similar to the experimental values. Once the loop starts to flex, it will occupy more volume, and the shape of the hairpin will be too complicated to model accurately. However, the spherical model is also too simplistic since it won't capture any details of loop conformational changes. Also important is that our data were acquired at temperatures sufficiently below the hairpin melting temperature that any contribution from a single-stranded state will be negligible.

The short depolarization component depends on the position of $2 \mathrm{AP}$ in the loop, supporting the interpretation that it measures local or segmental motion. Those 2AP in SLIV at the apex of the loops have the most rapid depolarization (350 psec, on average) which is independent of temperature over this range. This fast depolarization indicates that apical SLIV 2AP must experience rapid local motions, perhaps rotation about the glycosidic bond or flexibility of the phosphodiester backbone at what could be the turn of the loop. Curiously, 2AP at the apex of SLIV exhibits rapid depolarization even though it is flanked by a $3^{\prime}$ guanosine which is a good stacking partner. 2AP at the $3^{\prime}$ side of SLIV has a rapid anisotropy component that is only five times faster (1 nsec) than the slow component (5 nsec) at low temperature. At room temperature in low salt $(20 \mathrm{mM} \mathrm{KCl})$, SLIV loops experience local motions near their apex on the 350-psec timescale and, at the side, on the 800 -psec timescale.

Surprisingly, anisotropy of the SLII apical 2AP mimics the behavior of stacked $2 \mathrm{AP}$ at the $3^{\prime}$ side of SLIV, suggestive of local motions that are constrained by its context. This anisotropy component is temperature-dependent as well, with a value of $650 \mathrm{psec}$ at $20^{\circ} \mathrm{C}$. We conclude that the motions/dynamics of 2AP at the apex of SLII and SLIV are not the same, and therefore, the local structures of the two loops must differ.

The fractional contribution of each anisotropy component provides another indicator of loop and/or hairpin properties. In the case of $2 \mathrm{AP}$ on the $3^{\prime}$ side of SLIV, $65 \%$ of the depolarization occurs during global tumbling of the RNA at $5^{\circ} \mathrm{C}$, but at $40^{\circ} \mathrm{C}$, most of the signal is due to local segmental motions. In the case of apical 2AP in SLIV loops, the distribution is roughly $50: 50$ global:local at $5^{\circ} \mathrm{C}$, but 30:70 at $40^{\circ} \mathrm{C}$. Depolarization distributions of $2 \mathrm{AP}$ at the apex of SLII change from 60:40 to 20:80 over this temperature range. The increase in contributions from segmental motion at higher temperatures is consistent with enhanced loop flexibility that dominates fluorescence depolarization. The timescale of these motions are on the order of hundreds of picoseconds, but we note that the physical origins of the segmental motions cannot be determined from these data.

\section{Laser T-jump probes longer timescale dynamics}

These experiments required higher concentrations of RNA $(50 \mu \mathrm{M})$ to obtain the minimal signal required, since all the 2AP nucleobases are quenched to some extent in the loops. At this concentration, the RNA had to be kept in buffer with $20 \mathrm{mM} \mathrm{KCl}$ to avoid formation of dimers. Despite signal averaging, the signal in these experiments was weak. The temperature was jumped from $4^{\circ} \mathrm{C}$ to $9^{\circ} \mathrm{C}, 4^{\circ} \mathrm{C}$ to $10^{\circ} \mathrm{C}, 5^{\circ} \mathrm{C}$ to $13^{\circ} \mathrm{C}$, and from $13^{\circ} \mathrm{C}$ to $21^{\circ} \mathrm{C}$, and the fluorescence recorded for $1 \mathrm{msec}$ after each jump as the 
system re-equilibrated. The jumps that we were able to fit were described by a single exponential $S(t)=A e^{-t / \tau}+C$ (offset) where all three variables were allowed to float.

$2 \mathrm{AP}$ at the apex and sides of SLII and/or SLIV were used for these experiments, but only some of the data could be fit (Fig. 5), while other data, particularly the higher temperature jumps, showed no evidence of a change (data not shown). The time resolution of the apparatus is limiting here; we expect that the RNA does undergo more rapid transitions. Using the $3^{\prime}$ side 2AP in SLIV RNAs as a probe, we found that each SLIV loop had a relaxation time of $\sim 4 \mu \mathrm{sec}$ in jumps from $5^{\circ} \mathrm{C}$ to $13^{\circ} \mathrm{C}$; only hSLIV data could be fit from the jump $13^{\circ} \mathrm{C}$ to $21^{\circ} \mathrm{C}$, giving a relaxation time of $3 \mu \mathrm{sec}$. At the apex of the loop, 2AP in dSLIV showed a relaxation of 4 $\mu \mathrm{sec}$ (with an error of $\pm 3.7 \mu \mathrm{sec}$ making these data tentative; the actual relaxation time is probably faster) in a jump from $4^{\circ} \mathrm{C}$ to $9^{\circ} \mathrm{C}$, identical to the relaxation measured at the $3^{\prime}$ side. Perhaps these data report on a global conformational change of the dSLIV loop. However, data from apical 2AP in hSLIV could not be fit/showed no relaxation, suggesting that the two SLIV loops differ in their slow timescale dynamics. Apical 2AP in SLII had the longest relaxation time of $6 \mu \mathrm{sec}$ upon a $4^{\circ} \mathrm{C}$ to $10^{\circ} \mathrm{C}$ jump. The physical origin of this transition(s) shown in T-jump experiments is not clear. Menger et al. (2000) found that base stacking/unstacking occurred with a relaxation time of $<1$ $\mu s e c$, making it an unlikely source of the observed transitions at these temperatures. The $\sim 4 \mu \mathrm{sec}$ conformational change determined from the low-temperature T-jump experiments could be a global restructuring (breathing mode) of the loop, not local (segmental) motion of the 2AP. As such, this mode would represent correlated motions of nucleotides throughout the loop, perhaps a low frequency normal mode. We did not observe this relaxation at higher temperatures, possibly because the global mode had shifted to faster timescales, or because increased motion of the individual nucleotides precludes a global mode.

\section{snRNA loops in RNA:protein complexes}

The intrinsic dynamics of these loops are undoubtedly necessary for their interactions with their protein ligands. Although base stacking predominates at lower temperatures, at physiological temperature $\left(37^{\circ} \mathrm{C}\right)$, the bases are sampling other conformations, and the loop has become flexible. The bound conformations of the loops can be seen in the cocrystal structures from which the proteins have been removed (Fig. 6). The adenosine at the apex of the loops is stacked with phenylalanine in the U1A:SLII and $\mathrm{U}_{2} \mathrm{~B}^{\prime \prime}$ :SLIV complexes, but there are also sequence-specific contacts with this adenosine (Oubridge et al. 1994; Price et al. 1998; Nolan et al. 1999).

In the SLIV:U2B" cocrystal complex, the adenosine at the $3^{\prime}$ side of SLIV is not in contact with the protein and appears to be adjacent to the second protein in this complex, U2A'
(Price et al. 1998). This could be an artifact of crystal packing, however, if this side of the RNA loop is unstructured and flexible. To assess the properties of the complex in solution, we added Drosophila SNF RRM1 to dSLIV with 2AP at the $3^{\prime}$ side (Williams and Hall 2010). The substitution did not alter the dissociation constant (data not shown). A dramatic demonstration of the conformational change of dSLIV comes from the 1.5 -fold increase in fluorescence intensity of $2 \mathrm{AP}$ on the $3^{\prime}$ side upon binding to SNF (Fig. 6).

TCSPC data for 2AP on the $3^{\prime}$ side of dSLIV bound to SNF are fit by three exponential decay components, and the time-resolved anisotropy is fit with two depolarization components (Table 2). A significant difference between the bound and free RNA is observed in the anisotropy components. SLIV RNA bound to SNF has a longer rotational correlation time of $6.5 \mathrm{nsec}$, a little shorter than we expect for a complex with a molecular weight of $\sim 20$ $\mathrm{kDa}$ but twice as long as for the RNA alone. The shorter rotational correlation time, ascribed to local motions, is half as long as the corresponding depolarization in the free RNA, indicating more rapid local motion in the complex. This interpretation is consistent with the observed increase in the steady-state fluorescence intensity and suggests that this $2 \mathrm{AP}$ has been "flipped out" of its stacked state.

A similar experiment was carried out using the protein together with dSLIV with 2AP at its apex (Fig. 6). In the cocrystal complex, the apical adenosine is stacked over a phenylalanine sidechain (Price et al. 1998) but not stacked with another nucleobase. Binding of SNF to SLIV with apical $2 \mathrm{AP}$ resulted in a $\sim 25 \%$ increase in $2 \mathrm{AP}$ fluorescence. However, the binding affinity of SNF for apical 2AP SLIV RNA is greatly reduced from that of normal RNA (data not shown), indicating that critical interactions have been lost, either through loss of specific moieties on the nucleobases that make contact with protein or through steric interference by the presence of the 2 -amino group on $2 \mathrm{AP}$. If $2 \mathrm{AP}$ is not isosteric in the complex, then one explanation for its increased fluorescence intensity is that it is not constrained by the protein and is free to move. It is also possible that the environment in the complex is such that the 2AP fluorescence is enhanced, perhaps due to loss of stacking interactions with flanking nucleobases or by an induced electronic structure. Given this uncertainty in the binding mode of SLIV with this substitution, we did not continue with fluorescence experiments, since their interpretation with respect to the wildtype complex would be unclear.

\section{CONCLUSIONS}

The nucleobase motions within U1 SLII and U2 SLIV as described by 2-aminopurine fluorescence focus on the more rapid picosecond/nanosecond dynamics. Motions on this timescale come from rotations about the glycosidic bond, ribose repuckering, and backbone torsion angle 
A)

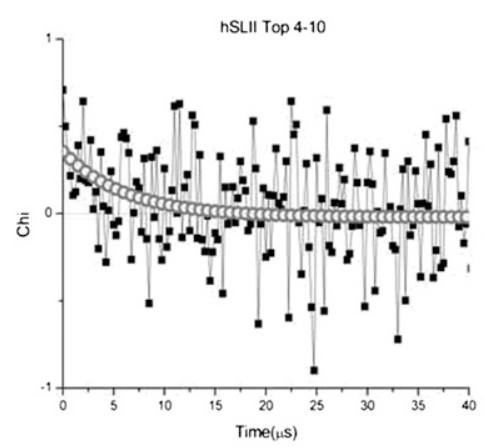

C)

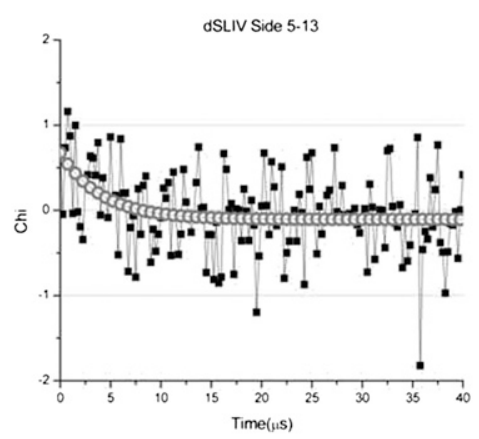

E)

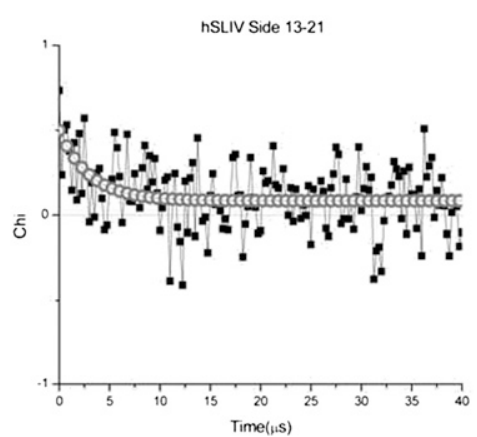

B)

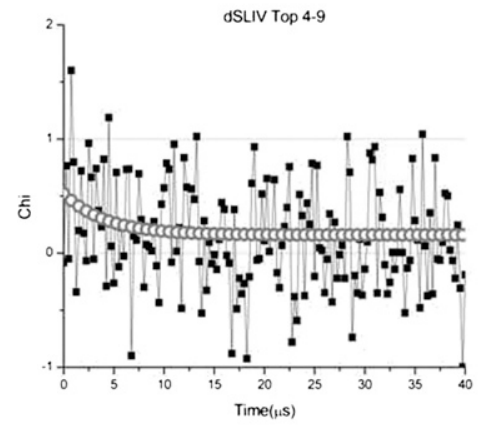

D)

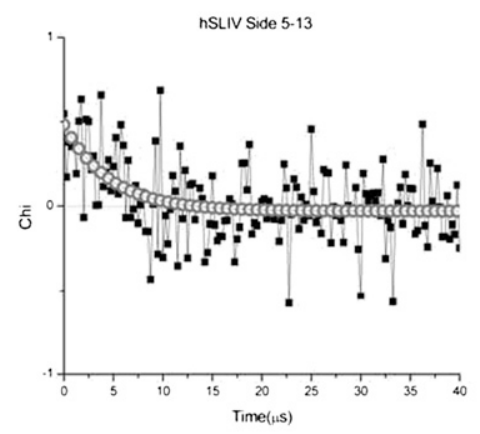

F)

\begin{tabular}{llrrrr} 
Hairpin & $\Delta \mathrm{T}\left({ }^{\circ} \mathrm{C}\right)$ & $\mathbf{T} \mathbf{(}(\boldsymbol{\mu})$ & $\mathbf{E r}(\mathbf{\pm})$ & \multicolumn{1}{c}{$\mathbf{A}$} & $\mathrm{Y}$ offset \\
\hline hSLII Apex & $4-10$ & 6.17 & 2.7 & 0.37 & -0.02 \\
dSLIV Apex & $4-9$ & 4.11 & 3.6 & 0.36 & -0.16 \\
dSLIV Side & $5-13$ & 4.08 & 1.8 & 0.78 & -0.1 \\
hSLIV Side & $5-13$ & 4.63 & 1.4 & 0.51 & -0.03 \\
hSLIV Side & $13-21$ & 3.01 & 1.1 & 0.41 & 0.08
\end{tabular}

FIGURE 5. Hairpin T-jump fluorescence relaxation. (A) hSLII, $4^{\circ} \mathrm{C}$ to $10^{\circ} \mathrm{C}$ jump. (B) dSLIV apex $2 \mathrm{AP}, 4^{\circ} \mathrm{C}$ to $9^{\circ} \mathrm{C}$ jump. (C) dSLIV $3^{\prime}$ side $2 \mathrm{AP}$, $5^{\circ} \mathrm{C}$ to $13^{\circ} \mathrm{C}$ jump. $(D)$ hSLIV $3^{\prime}$ side $2 \mathrm{AP}, 5^{\circ} \mathrm{C}$ to $13^{\circ} \mathrm{C}$ jump. (E) hSLIV $3^{\prime}$ side $2 \mathrm{AP}, 13^{\circ} \mathrm{C}$ to $21^{\circ} \mathrm{C}$ jump. $\chi$ values $(\mathbf{\square})$ for each bin are shown with connecting lines (see Materials and Methods). Fits to a single exponential decay are plotted on the decay data $(O \bigcirc \bigcirc)$. $(F)$ Table of relaxation times for each RNA. Error is from the fit. A is the amplitude prefactor, $\mathrm{Y}$ is the offset.

changes, but here the physical origins of the motions must be inferred, since only the nucleobase is directly monitored. The level of detailed description of loop rearrangements is thus restricted, but by monitoring multiple sites within the loop, we are able to make several conclusions regarding the local and global conformational changes of these long loops. These rapid motions are on the timescales accessible to molecular dynamics simulations which could provide an integrated time-dependent description of their motions.
The timescales probed by these experiments vary from hundreds of picoseconds to microseconds and presumably represent different conformational transitions. A time line of the fluorescence measurements, together with a conceptual interpretation of the data, are shown in Figure 7. It is apparent that the nanosecond motions of the bases are not correlated; at least the apex of the loop is not coupled to the sides. This observation might be anticipated from the composition and length of the loop, but the measurements provide a quantified description. In contrast, the timescale of 


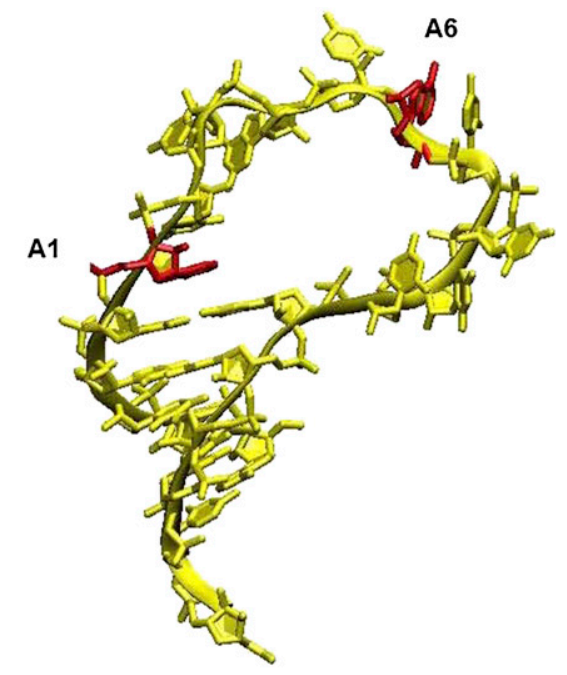

SLII

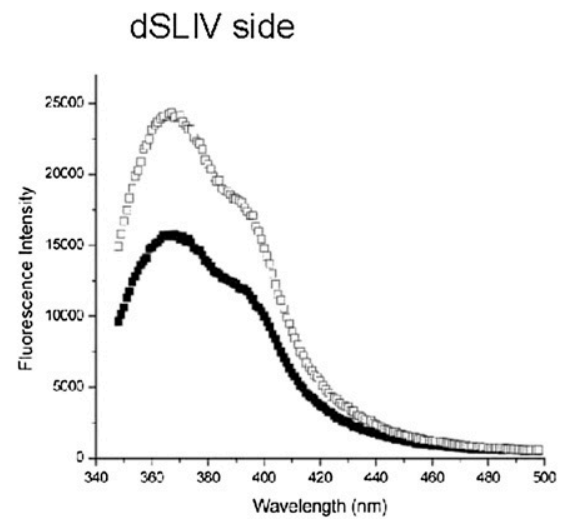

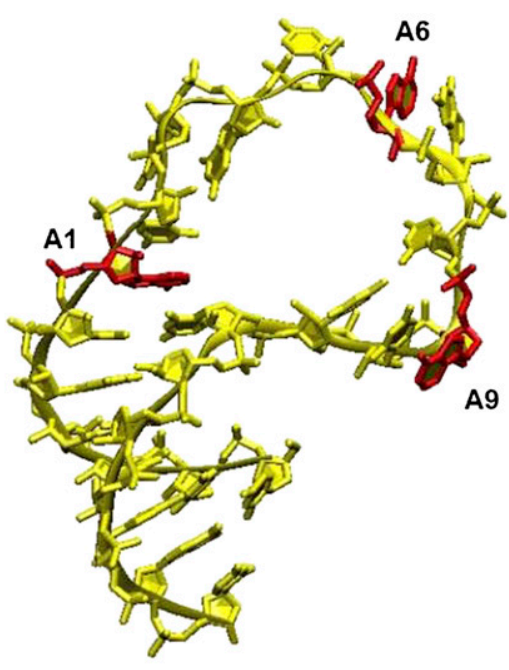

SLIV

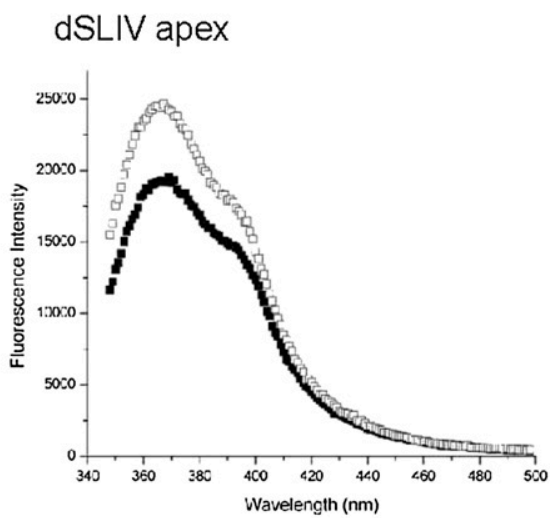

FIGURE 6. SLII and SLIV bound to proteins. (Upper left) Human SLII structure when bound to U1A RRM1 (1urn). (Upper right) Human SLIV structure bound to rabbit U2B" (1a9n). In these two panels, the protein was removed to display the RNA alone using VMD (Humphrey et al. 1996). Sites of 2AP replacement are indicated. (Lower left) Steady-state fluorescence of 2AP on the $3^{\prime}$ side of dSLIV free ( $\square$ ) and bound ( $\square$ ) to Drosophila SNF RRM1 in $20 \mathrm{mM} \mathrm{KCl}$. (Lower right) Steady-state fluorescence of 2AP on the apex of dSLIV free (ם) and bound ( $\square$ ) to Drosophila SNF RRM1 in $20 \mathrm{mM} \mathrm{KCl}$.

the transition represented in T-jump experiments is consistent for both apical and side 2AP, suggesting that this transition could be global. More data are required to establish the type of loop conformational change reported by T-jump experiments.

Extrapolating from the properties of 2AP, a general conclusion is that all the nucleobases in the loops experience stochastic local motions. 2AP substitutions occur within sequences that are most likely to be stacked with neighboring nucleobases, and indeed, 2AP at the $5^{\prime}$ end of the loop is very stably stacked on the loop-closing base pair. The other adenines experience significant local motions, spending only a fraction of their time in stacking interactions. These fluorescence data show that the most flexible (floppy) part

TABLE 2. 2AP fluorescence in dSLIV free and bound to SNF RRM1

\begin{tabular}{|c|c|c|c|c|c|c|c|c|}
\hline Time-resolved fluorescence & $\mathrm{T}\left({ }^{\circ} \mathrm{C}\right)$ & $\tau_{1}$ (nsec) & $\beta_{1}$ & $\tau_{2}$ (nsec) & $\beta_{2}$ & $\tau_{3}$ (nsec) & $\beta_{3}$ & $\chi^{2}$ \\
\hline dSLIV & 20 & 7.29 & 0.11 & 2.35 & 0.16 & 0.21 & 0.73 & 2.01 \\
\hline $\mathrm{dSLIV}+\mathrm{SNF}$ & 20 & 7.97 & 0.09 & 2.26 & 0.13 & 0.17 & 0.77 & 2.22 \\
\hline Anisotropy & $\mathrm{T}\left({ }^{\circ} \mathrm{C}\right)$ & $R_{o}$ & $\Phi_{1}$ (nsec) & $\beta_{1}(\%)$ & $\varphi_{2}$ (nsec) & $\beta_{2}(\%)$ & $x^{2}$ & \\
\hline dSLIV & 20 & 0.26 & 3.2 & 50 & 0.81 & 50 & 1.05 & \\
\hline $\mathrm{dSLIV}+\mathrm{SNF}$ & 20 & 0.34 & 6.5 & 47 & 0.41 & 53 & 1.66 & \\
\hline
\end{tabular}

$2 \mathrm{AP}$ on the $3^{\prime}$ side of dSLIV. [dSLIV] $=2 \mu \mathrm{M}$; [SNF] $=2.2 \mu \mathrm{M} .20 \mathrm{mM} \mathrm{KCl}, 10 \mathrm{mM}$ sodium cacodylate, pH 7.4. Data fit using FluoFit. Errors in amplitudes $\pm 5 \%$ of the value $(50 \pm 2.5 \%)$. $R_{o}$ is the anisotropy at $t=0$. 


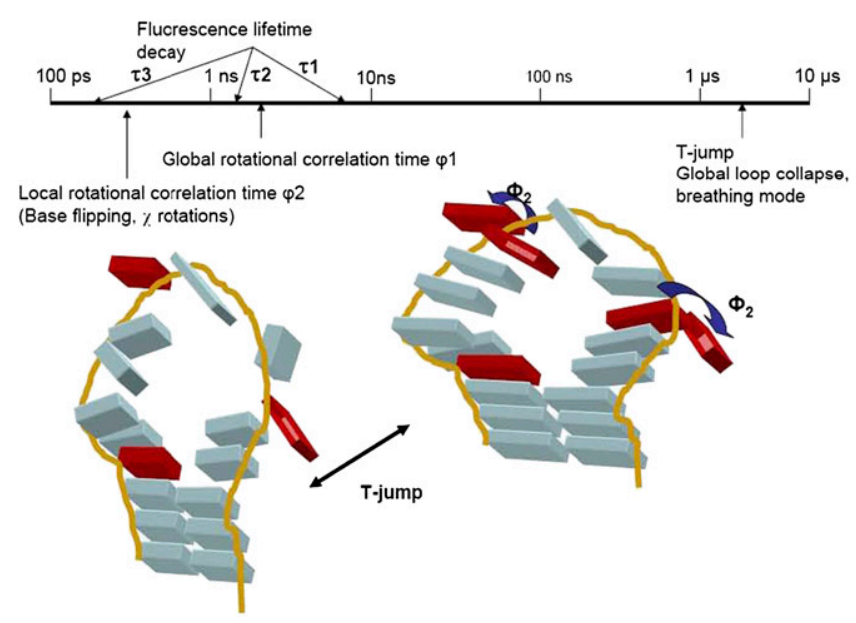

FIGURE 7. A summary of the fluorescence timescales measured and a model of their physical origin. The time line is logarithmic. A model of SLIV is used: 2AP sites are shown in red, with their possible conformational transitions illustrated. 2AP at the apex and on the $3^{\prime}$ side are shown stacked and flipped out, corresponding to timeresolved fluorescence data. These events are not correlated. In contrast, we model the conformational transition reported by T-jump as a global reordering of the loop, or perhaps as a breathing mode (a low-frequency normal mode).

of the loop is at the apex where, presumably, the chain turns. The 2AP at this position spends a significant amount of time free of base stacking interactions, so it would be available for stacking interactions with exposed aromatic amino acids on the surface of the protein. This is a key stacking interaction in the U1A:SLII complex (Shiels et al. 2002) that positions the adenosine for specific hydrogen bonding interactions with the protein. If the first contact between RNA and protein occurs via the nucleobases at the apex of the loop, the change in their orientations could propagate down the phosphodiester backbone on both sides to destabilize loop base stacking.

There is a gap between $10 \mathrm{nsec}$ and $1 \mu \mathrm{sec}$ in our measurements, due in part to the intrinsic photophysics of $2 \mathrm{AP}$. If $2 \mathrm{AP}$ had a longer fluorescence lifetime, we could detect motions on longer timescales if they were present. We are left with missing information on transitions with rates of $10^{-8}$ to $10^{-6} \mathrm{sec}^{-1}$, which is a biologically important window. Binding of SLII to U1A as measured by surface plasmon resonance gave on-rates on the order of $10^{7} \mathrm{~mol}^{-1} \mathrm{sec}^{-1}$ (Law et al. 2006), which is slower than diffusion-controlled associations and consistent with a requisite conformation change of one or both components. We predict that there are loop motions on this timescale, which we could possibly measure using NMR methods.

Does the ensemble of RNA loop conformations in its free state contain some population of the bound conformation, as assumed by the conformational capture mechanism? Does it need to sample this state in order to make initial productive contact with the protein ligands, or are there mutually induced conformations of RNA loop and protein following an initial interaction-the induced fit binding model? Among all the possible conformations accessible to the loops, certainly some of them would be competent to bind protein whether via conformational capture or induced fit. Binding would be entropically unfavorable since it reduces the ensemble of conformational states, but stacking with aromatic amino acids and formation of protein:RNA hydrogen bonds presumably compensate. The energetics of binding to proteins for SLII and SLIV are complicated: temperature dependent with entropy/enthalpy compensation, some with a measurable heat capacity, all salt-dependent (Williams and Hall 1996, 2010, 2011), and with on- and off-rates that imply complex interaction schemes (Katsamba et al. 2001; Law et al. 2006; Anunciado et al. 2011). Certainly some of the thermodynamic and kinetic challenges to formation of the RNA:protein complexes are due to the conformational heterogeneity of the large RNA loops, but the subsequent ability of the loop to adapt to the protein binding surface is key to formation of the high affinity complexes.

\section{MATERIALS AND METHODS}

\section{RNA stem-loops}

The RNA hairpins used were derived from U1 snRNA Stem-loop II and U2 snRNA Stem-loop IV of human and Drosophila. The stem sequence was the same for each RNA across all constructs made. Unlabeled RNA stem-loops were transcribed using T7 RNA Polymerase as described in Milligan et al. (1987). DNA primers were purchased from IDT. The 2-aminopurine (2AP) label $\left(A^{*}\right)$ RNA stem-loops were purchased from either Dharmacon or IBA; each RNA contained only one 2AP. The buffer used for all fluorescence and UV experiments was $2.5 \mathrm{mM}$ sodium cacodylate $\mathrm{pH} 7.4$, and $250 \mu \mathrm{M}$ EDTA with salt concentration of 0,20 , or 100 $\mathrm{mM} \mathrm{KCl}$. The $\mathrm{pH}$ of the buffer increases to 8 at $90^{\circ} \mathrm{C}$, but because $2 \mathrm{AP}$ has a $\mathrm{pK}_{\mathrm{a}}=12$ (Ward et al. 1969), its protonation state should be unchanged in these experiments. RNA concentrations were $2 \mu \mathrm{M}$ for most experiments; the concentration was $50 \mu \mathrm{M}$ for the T-jump experiments.

\section{hSLII $5^{\prime}-$ GGCCGCA ${ }^{\star}$ UUGCA $^{\star}$ CUCCGCGGCC $-3^{\prime}$ hSLIV $5^{\prime}$-GGCCGUA ${ }^{\star}$ UUGCA $^{\star} \mathrm{GUA}^{\star}{ }^{*}$ CCUCGGCC $-3^{\prime}$

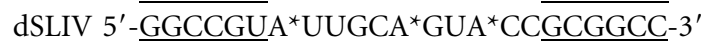

\section{Protein}

Drosophila SNF RRM1 was purified as described in Williams and Hall (2010).

\section{Absorbance melts}

Thermal melts were carried out using a Gilford 260 spectrophotometer, which was fitted with a 2527 Gilford thermoprogrammer. All samples were heated to $95^{\circ} \mathrm{C}$, then snap-cooled on ice to ensure proper folding of the RNA stem-loops. Samples were heated at a rate of $1^{\circ} \mathrm{C} / \mathrm{min}$ from $5^{\circ} \mathrm{C}-90^{\circ} \mathrm{C}$ as the absorbance was 
recorded at $260 \mathrm{~nm}$. All thermal melts were fit using a two-state model programmed in Origin. The concentration dependence of RNA melting was measured using 2, 10, 20, and $50 \mu \mathrm{M}$ RNAs in the different salt conditions to look for evidence of dimer formation.

\section{Fluorescence melts}

Fluorescence melts were performed using a PTI (Photon Technology International) equipped with a Xenon compact arc lamp set at $70 \mathrm{~W}$, a model 810 PMT set at $1000 \mathrm{~V}$, and a water bath for temperature control. Fluorescence melts were carried out at an excitation wavelength of $300 \mathrm{~nm}$ and an emission wavelength of $366 \mathrm{~nm}$, which was found to be the maximum for these samples. The excitation and emission slits were $2 \mathrm{~nm}$ for all samples. Samples were heated at a programmed temperature gradient, and temperature was monitored with a thermistor. Salt-dependent fluorescence melts were performed on SLM 8100 equipped with a Xenon arc lamp and polarizers which were set to the magic angle $55^{\circ}$. PMT voltages were set to achieve $\sim 10,000$ counts. Excitation and emission wavelengths were identical to those used on the PTI, although the slits for excitation and emission were set at $8 \mathrm{~nm}$. Samples were heated as on the PTI, although temperature was monitored with a thermocouple. Uncorrected emission spectra of protein (SNF)-bound and free RNA were collected at $20^{\circ} \mathrm{C}$.

\section{Time domain lifetime/anisotropy}

All lifetime measurements were performed on a home built timecorrelated single photon counting instrument as described (Jean and Hall 2004). A Ti:Sapphire laser was pulse picked and tripled to excite the $2 \mathrm{AP}$ using $300 \mathrm{~nm}$. Samples were cooled and heated using a water bath, and the temperature was monitored using a thermistor. Lifetime and IRF decay curves were collected until overflow $\left(65,536\right.$ counts) with the polarizer at $55^{\circ}$ (an example is shown in Supplemental Fig. S1). IRF was collected with a $1 / 100$ dilution of LUDOX (Aldrich) solution; its FWHM was measured every day and varied from $215-222$ psec. Anisotropy decays were collected in separate runs where vertical polarization was collected first to overflow, then horizontal polarization was collected with the same acquisition time. Fluofit 4.4 (Picoquant) was used to fit both lifetime and anisotropy curves. Fluorescence lifetime decays were best fit with a three-component exponential model with reconvolution. Anisotropy decays were fit using a two-component exponential model. The G-factor was calculated using tail matching. Buffer scattering accounted for $<5 \%$ of the counts in the peak channel; it was not subtracted from the decay curves. Goodness of fit was assessed by support plane analysis.

\section{T-jump}

All temperature jump experiments were done at the University of Illinois, Urbana-Champaign in the Gruebele Lab on their custombuilt apparatus (Ballew et al. 1996; Sarkar et al. 2009). The samples were excited at $280 \mathrm{~nm}$ by a Ti:Sapphire laser that was tripled. Temperature perturbation pulse was generated by a Nd:YAG laser that was Raman shifted to $1900 \mathrm{~nm}$, then split to be focused on the cuvette from both sides. The magnitude of the jump was calibrated by a $300-\mu \mathrm{M}$ L-tryptophan sample in which the lifetime decay curve after the jump was matched to the lifetime decay curve obtained at that approximate temperature at steady state. Jump size varied for each experiment, ranging from $5^{\circ} \mathrm{C}$ to $8^{\circ} \mathrm{C}$. Starting temperatures were maintained using a Peltier device. RNA samples were at $50-\mu \mathrm{M}$ concentration in $20 \mathrm{mM} \mathrm{KCl}$ to obtain maximum signal-to-noise ratio without dimers forming. Capillary cuvettes had a path length of $200 \mu \mathrm{m}$. The data were processed in Matlab using $\chi$ analysis scripts supplied from the Gruebele Lab. The $\chi$ value is a model-free parameter describing the similarity of the normalized lifetime curves acquired after the jump to both an initial curve $(f 1)$ acquired before the jump and a final curve $(f 2)$ acquired after the jump when the molecule has attained thermal equilibrium. The curves during the transition are fit to a linear combination of $\mathrm{A}^{\star} f 1+\mathrm{B}^{\star} f 2$, and $\chi$ is calculated from the fit results $\mathrm{A}$ and $\mathrm{B}$ as $\chi=$ $\mathrm{A} /(\mathrm{A}+\mathrm{B})$. Lifetime curves are acquired every $12.5 \mathrm{nsec}$; to increase signal-to-noise, we normally binned 20 such curves before fitting, giving a time resolution of $250 \mathrm{nsec}$ for the $\chi$ time traces. Starting $0.25 \mu \mathrm{sec}$ after the jump, the traces were fit to a single exponential decay model.

\section{SUPPLEMENTAL MATERIAL}

Supplemental material is available for this article.

\section{ACKNOWLEDGMENTS}

We thank Professor Martin Gruebele and Hannah Gelman from the University of Illinois, Urbana-Champaign, for allowing us to use their T-jump apparatus and for help with data processing. This work was funded by NIH R01 GM096444 to K.B.H.

Received June 18, 2012; accepted August 2, 2012.

\section{REFERENCES}

Anunciado D, Dhar A, Gruebele M, Baranger AM. 2011. Multistep kinetics of the U1A-SL2 RNA complex dissociation. J Mol Biol 408: 896-908.

Ballew RM, Sabelko J, Gruebele M. 1996. A single-sweep, nanosecond time resolution laser temperature-jump apparatus. Rev Sci Instrum 67: 3694-3699.

Burkard ME, Kierzek R, Turner DH. 1999. Thermodynamics of unpaired terminal nucleotides on short RNA helices correlates with stacking at helix termini in larger RNAs. J Mol Biol 290: 967-982.

Correll CC, Wool IG, Munishkin A. 1999. The two faces of the Escherichia coli $23 \mathrm{~S}$ rRNA sarcin/ricin domain: The structure at 1.11 A resolution. J Mol Biol 292: 275-287.

Correll CC, Beneken J, Plantinga MJ, Lubbers M, Chan YL. 2003. The common and the distinctive features of the bulged-G motif based on a $1.04 \AA$ resolution RNA structure. Nucleic Acids Res 31: 6806-6818.

Flickinger TW, Salz HK. 1994. The Drosophila sex determination gene snf encodes a nuclear protein with sequence and functional similarity to the mammalian U1A snRNP protein. Genes Dev 8: 914-925.

Frankel AD, Smith CA. 1998. Induced folding in RNA-protein recognition: More than a simple molecular handshake. Cell 92: 149-151.

Humphrey W, Dalke A, Schulten K. 1996. VMD: Visual molecular dynamics. J Mol Graph 14: 33-38.

Jean JM, Hall KB. 2001. 2-Aminopurine fluorescence quenching and lifetimes: Role of base stacking. Proc Natl Acad Sci 98: 37-41.

Jean JM, Hall KB. 2002. 2-Aminopurine electronic structure and fluorescence properties in DNA. Biochemistry 41: 13152-13161.

Jean JM, Hall KB. 2004. Stacking-unstacking dynamics of oligodeoxynucleotide trimers. Biochemistry 43: 10277-10284. 
Katsamba PS, Myszka DG, Laird-Offringa IA. 2001. Two functionally distinct steps mediate high affinity binding of U1A protein to U1 hairpin II RNA. J Biol Chem 276: 21476-21481.

Kormos BL, Baranger AM, Beveridge DL. 2007. A study of collective atomic fluctuations and cooperativity in the U1A-RNA complex based on molecular dynamics simulations. J Struct Biol 157: 500-513.

Krol A, Westhof E, Bach M, Lührmann R, Ebel JP, Carbon P. 1990. Solution structure of human U1 snRNA. Derivation of a possible three-dimensional model. Nucleic Acids Res 18: 3803-3811.

Lakowicz JR. 2006. Principles of fluorescence spectroscopy, 3rd ed. Springer Press, New York.

Law MJ, Rice AJ, Lin P, Laird-Offringa IA. 2006. The role of RNA structure in the interaction of U1A protein with U1 hairpin II RNA. RNA 12: 1168-1178.

Luchansky SJ, Nolan SJ, Baranger AM. 2000. Contribution of RNA conformation to the stability of a high-affinity RNA-protein complex. J Am Chem Soc 122: 7130-7131.

Menger M, Eckstein F, Porschke D. 2000. Dynamics of the RNA hairpin GNRA tetraloop. Biochemistry 39: 4500-4507.

Milligan JF, Groebe DR, Witherell GW, Uhlenbeck OC. 1987. Oligoribonucleotide synthesis using T7 RNA polymerase and synthetic DNA templates. Nucleic Acids Res 15: 8783-8798.

Nolan SJ, Shiels JC, Tuite JB, Cecere KL, Baranger AM. 1999. Recognition of an essential adenine at a protein-RNA interface: Comparison of the contributions of hydrogen bonds and a stacking interaction. J Am Chem Soc 121: 8951-8952.

Oubridge C, Ito N, Evans PR, Teo CH, Nagai K. 1994. Crystal structure at $1.92 \AA$ resolution of the RNA-binding domain of the U1A spliceosomal protein complexed with an RNA hairpin. Nature 372: 432-438.

Pitici F, Beveridge DL, Baranger AM. 2002. Molecular dynamics simulation studies of induced fit and conformational capture in U1A-RNA binding: Do molecular substrates code for specificity? Biopolymers 65: 424-435.

Polycarpou-Schwartz M, Gunderson SI, Kandels-Lewis S, Seraphin B, Mattaj I. 1996. Drosophila SNF/D25 combines the functions of the two snRNP proteins U1A and U2B" that are encoded separately in human, potato, and yeast. RNA 2: 11-23.

Price SR, Evans PR, Nagai K. 1998. Crystal structure of the spliceosomal $\mathrm{U} 2 \mathrm{~B}^{\prime \prime}-\mathrm{U} 2 \mathrm{~A}^{\prime}$ protein complex bound to a fragment of U2 small nuclear RNA. Nature 394: 645-650.

Qin F, Chen Y, Wu M, Li Y, Zhang J, Chen H. 2010. Induced fit or conformational selection for RNA U1A folding. RNA 16: 1053-1061.

Query CC, Bentley RC, Keene JD. 1989. A specific 31-nucleotide domain of U1 RNA directly interacts with the 70K small nuclear ribonucleoprotein component. Mol Cell Biol 9: 4872-4881.
Reddy R, Henning D, Epstein P, Busch H. 1981. Primary and secondary structure of U2 snRNA. Nucleic Acids Res 9: 5645-5658.

Sarkar K, Meister K, Sethi A, Gruebele M. 2009. Fast folding of an RNA tetraloop on a rugged energy landscape detected by a stacking-sensitive probe. Biophys J 97: 1418-1427.

Scherly D, Boelens W, van Venrooij WJ, Dathan NA, Hamm J, Mattaj IW. 1989. Identification of the RNA binding segment of human U1 A protein and definition of its binding site on U1 snRNA. EMBO J 8: 4163-4170.

Scherly D, Dathan NA, Boelens W, van Venrooij WJ, Mattaj IW. 1990. The U2B" RNP motif as a site of protein-protein interaction. EMBO J 9: 3675-3681.

Serra MJ, Barnes TW, Betschart K, Gutierrez MJ, Sprouse KJ, Riley CK, Stewart L, Temel RE. 1997. Improved parameters for the prediction of RNA hairpin stability. Biochemistry 36: 48444851.

Shajani Z, Varani G. 2005. 13C NMR relaxation studies of RNA base and ribose nuclei reveal a complex pattern of motions in the RNA binding site for human U1A protein. J Mol Biol 349: 699-715.

Shajani Z, Drobny G, Varani G. 2007. Binding of U1A protein changes RNA dynamics as observed by 13C NMR relaxation studies. Biochemistry 46: 5875-5883.

Shiels JC, Tuite JB, Nolan SJ, Baranger AM. 2002. Investigation of a stacking interaction in target site recognition by the U1A protein. Nucleic Acids Res 30: 550-558.

Showalter SA, Hall KB. 2002. A functional role for correlated motion in the N-terminal RNA-binding domain of human U1A protein. J Mol Biol 322: 533-542.

Showalter SA, Hall KB. 2004. Altering the RNA-binding mode of the U1A RBD1 protein. J Mol Biol 335: 465-480.

Showalter SA, Hall KB. 2005. Correlated motions in the U1 snRNA stem/loop 2:U1A RBD1 complex. Biophys J 89: 2046-2058.

Ward DC, Reich E, Stryer L. 1969. Fluorescence studies of nucleotides and polynucleotides. Biol Chem 5: 1228-1237.

Williams DJ, Hall KB. 1996. RNA hairpins with non-nucleotide spacers bind efficiently to the human U1A protein. $J$ Mol Biol 257: 265-275.

Williams SG, Hall KB. 2010. Coevolution of Drosophila snf protein and its snRNA targets. Biochemistry 49: 4571-4582.

Williams SG, Hall KB. 2011. Human U2B" protein binding to snRNA stemloops. Biophys Chem 159: 82-89.

Williamson JR. 2000. Induced fit in RNA-protein recognition. Nat Struct Biol 7: 834-837.

Zuker M. 2003. Mfold web server for nucleic acid folding and hybridization prediction. Nucleic Acids Res 31: 3406-3415. 

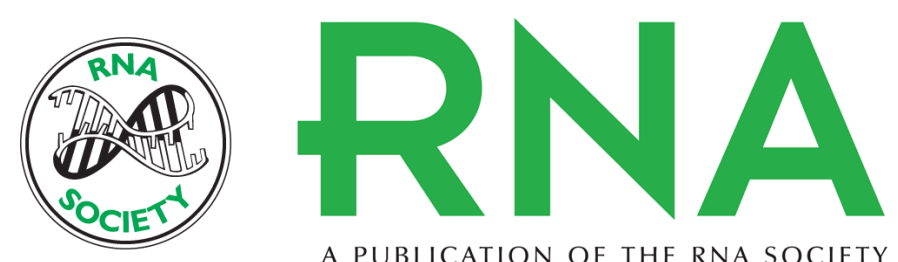

A PUBLICATION OF THE RNA SOCIETY

\section{Intrinsic flexibility of snRNA hairpin loops facilitates protein binding}

Michael Rau, W. Tom Stump and Kathleen B. Hall

RNA 2012 18: 1984-1995 originally published online September 25, 2012

Access the most recent version at doi:10.1261/rna.035006.112

Supplemental

Material

References

\section{License}

Email Alerting

Service
http://rnajournal.cshlp.org/content/suppl/2012/09/04/rna.035006.112.DC1

This article cites 42 articles, 7 of which can be accessed free at:

http://rnajournal.cshlp.org/content/18/11/1984.full.html\#ref-list-1 